\title{
De praktijkondersteuner in de huisartspraktijk: competentieprofiel en dagelijkse praktijk
}

\author{
I.B.O.M. Lohman, A.R.S. Wijsbeek, F.W. Dijkers, A.P. Timmers, E. Zonnevylle, \\ P.B.M. van der Linden, T.P.M. Vliet Vlieland
}

\section{Samenvatting}

Inleiding: Sinds 2001 worden praktijkondersteuners opgeleid met als belangrijkste doel om de werkdruk in de huisartspraktijk te verminderen. Doel van het onderzoek was na te gaan in hoeverre het takenpakket en de competenties die in de opleiding tot praktijkondersteuner aan de orde komen in de dagelijkse praktijk worden uitgevoerd en of er sprake is van andere taken of uitbreiding van taken. Ook de aansluiting van de opleiding op de praktijk is onderzocht.

Methode: 76 praktijkondersteuners werkzaam in de regio van de Districts Huisartsenvereniging Rijnland en Midden-Holland kregen een vragenlijst opgestuurd. Deze bestond uit in totaal 54 meerkeuze- en open vragen betreffende opleiding en ervaring, de huidige werksituatie en werkzaamheden, de uitvoering van het kwaliteitsbeleid en opvattingen over de aansluiting tussen opleiding en dagelijkse praktijk.

Resultaten: De respons bedroeg 50/76 (66\%). Alle respondenten waren vrouw, de mediane leeftijd was 43 jaar (range 24-61) en de mediane duur van hun werkzaamheden als praktijkondersteuner was 18 maanden (range 0-72). Het mediane aantal aandachtsgebieden per praktijkondersteuner was 4 (range 1-6), waarbij diabetes mellitus ( $n=43,86 \%)$, astma en chronic obstructive pulmonary disease (COPD) $(n=38,76 \%)$, en hart- en vaatziekten $(n=25,50 \%)$ de meest genoemde aandachtsgebieden waren. Voor sociale visites bedroeg het aantal (percentage) respondenten dat dit tot een aandachtsgebied rekende 18 (36\%), voor ouderenzorg 16 (32\%), wondverzorging 11 (22\%), de organisatie van de huisartspraktijk 10 (20\%), gezondheidsvoorlichting en -opvoeding $7(14 \%)$ en overig 15 (30\%). Het bij de start van de functie 'praktijkondersteuner' opgestelde plan van aanpak is door 24 (48\%) van de praktijkondersteuners geëvalueerd en dit heeft in ongeveer de helft van de gevallen geleid tot bijstellingen. Dertig procent van de praktijkondersteuners evalueerde de kwaliteit van zorg systematisch, waarbij metingen van kwaliteit van zorg relatief weinig voorkwamen (regelmatige effectiviteitsmetingen in $12 \%$ en tevredenheidsmetingen in $4 \%$ ). De meest genoemde aandachtspunten (>25\%) voor toekomstige nascholing waren: ziektebeelden, medicatie, diagnostiek en methodisch handelen, computervaardigheden en kwaliteitsbeleid. De algehele satisfactie met de eigen functie was hoog.

Conclusies: De praktijkondersteuner voert, naast de taken behorend bij de aandachtsgebieden waar zij voor is opgeleid, aanvullende taken op verschillende gebieden uit. Bijna de helft van de respondenten evalueert op systematische wijze het kwaliteitsbeleid en de kwaliteit van zorg, maar effect- en tevredenheidsmetingen komen nog nauwelijks voor. De aansluiting van de opleiding tot praktijkondersteuner met de dagelijkse praktijk is op verschillende punten voor verbetering vatbaar. (Lohman IBOM, Wijsbeek ARS, Dijkers FW, Timmers AP, Zonnevylle E, Linden PBM van der, Vliet Vlieland TPM. De praktijkondersteuner in de huisartspraktijk: competentieprofiel en dagelijkse praktijk. Tijdschrift voor Medisch Onderwijs 2006;25(1):29-38.)

\section{Inleiding}

Door een aantal ontwikkelingen in de eerstelijnsgezondheidszorg is er in de af- gelopen jaren behoefte ontstaan aan praktijkondersteuning in de huisartspraktijk. ${ }^{1-2}$ Om de gewenste praktijkondersteuning 
concreet vorm te geven is in juni 1999 een convenant 'Huisartsenzorg' ondertekend door de Landelijke Huisartsenvereniging (LHV), het Ministerie van Volksgezondheid, Welzijn en Sport (WVS) en de Zorgverzekeraars Nederland (ZN). Dit convenant betrof de invoering van praktijkondersteuning op HBO-niveau (POH).

De LHV heeft in april 2001, in samenwerking met enkele hogescholen, competenties en eindtermen geformuleerd voor een opleiding tot praktijkondersteuner in de huisartspraktijk. ${ }^{3}$ Tot de kerntaken van een praktijkondersteuner behoort het verlenen van consulten in de vorm van spreekuren aan met name patiënten met diabetes mellitus type 2 en astma/COPD. In de herziene versie van het werkdocument van 2004 zijn de aandachtsgebieden uitgebreid met hart- en vaatziekten. ${ }^{4}$

De opleiding tot praktijkondersteuner kent twee varianten: een eenjarige opleiding voor verpleegkundigen met een HBO-diploma verpleegkunde (VK HAP - verpleegkundige in de huisartspraktijk) en een tweejarige opleiding voor doktersassistenten of verpleegkundigen met een diploma op MBO-niveau (LPO - leergang praktijkondersteuning).

Volgens recente cijfers van de LHV zijn in de afgelopen vier jaar ruim 3.000 huisartsen in Nederland gaan werken met een praktijkondersteuner ${ }^{5}$ en zijn in totaal 1.100 praktijkondersteuners in de huisartspraktijk werkzaam. ${ }^{2}$

De tot nu toe verrichtte onderzoeken naar het functioneren van de praktijkondersteuner waren met name gericht op de mate waarin objectieve werkdrukvermindering van huisartsen werd gerealiseerd, op patiëntensatisfactie en op de kwaliteit van de zorgverlening voor chronisch zieken. ${ }^{2}$ Uit deze onderzoeken is gebleken dat over het algemeen het effect op de objectieve werkdruk van de huisarts gering is. ${ }^{6}$ Zowel de huisarts als de patiënt zijn echter tevreden en ervaren een verbetering van de kwaliteit van zorg; dit gold met name voor patiënten met astma/COPD. 6

In de beschikbare publicaties is weinig informatie te vinden over de inhoud, uitvoering en kwaliteitsborging van de werkzaamheden van de praktijkondersteuner en de aansluiting van de genoten opleiding bij de uitgevoerde taken. Het doel van het in dit artikel beschreven onderzoek was dan ook na te gaan binnen welke aandachtsgebieden de praktijkondersteuner werkzaam is en op welke wijze de kwaliteit van de zorgverlening door de praktijkondersteuner wordt geborgd. Tevens werd onderzocht in hoeverre de opleiding tot praktijkondersteuner aansluit bij de in de dagelijkse praktijk uitgevoerde werkzaamheden.

\section{Methode}

\section{Onderzoeksopzet}

Het inventariserende, beschrijvende onderzoek werd uitgevoerd door de kenniskring Mensen met een Chronische Ziekte van de Hogeschool Leiden, in samenwerking met de afdeling Huisartsgeneeskunde en Verpleeghuisgeneeskunde van het Leids Universitair Medisch Centrum (LUMC), het Gezondheidscentrum Wantveld te Noordwijk en de Districts Huisartsenvereniging (DHV) Rijnland en MiddenHolland.

\section{Onderzoekspopulatie}

Voor het vaststellen van een lijst van potentiële respondenten werd gebruik gemaakt van een bestand van de DHV Rijnland en Midden-Holland met de namen en adressen van 76 praktijkondersteuners.

\section{Vragenlijst}

De vragenlijst bestond uit drie delen en bevatte in totaal 58 vragen. De meeste vragen dienden in meerkeuzevorm te worden 
beantwoord. Er werden vragen gesteld op de volgende gebieden:

1. Algemene gegevens.

2. Taken, verantwoordelijkheden en werkzaamheden van de praktijkondersteuner.

3. De afstemming tussen theorie en praktijk en de arbeidssatisfactie.

De vragenlijst ging vergezeld van een aanbevelingsbrief van de afdeling Huisartsgeneeskunde en Verpleeghuisgeneeskunde van het LUMC en van de DHV Rijnland en Midden-Holland. Bij de vragenlijst en de begeleidende brief werd een apart antwoordkaartje meegestuurd, waardoor duidelijk werd welke respondenten een ingevulde vragenlijst hadden teruggestuurd. De anonimiteit van de respondent werd gewaarborgd. Twee weken na het versturen van de vragenlijst werden de praktijkondersteuners van wie geen antwoordkaartje was ontvangen schriftelijk benaderd met het verzoek om de vragenlijst alsnog in te vullen. Wanneer daarop niet werd gereageerd, volgde een telefonisch verzoek.

\section{Resultaten}

\section{Respons}

De vragenlijst werd in maart 2004 verstuurd naar 76 praktijkondersteuners. In eerste instantie werden 38 (50\%) vragenlijsten geretourneerd. Vervolgens werd een reminder gestuurd naar de 38 praktijkondersteuners die nog niet hadden gereageerd. Dit leverde nog 10 (13\%) reacties op. Ten slotte werden nog 16 mensen telefonisch benaderd, waarvan er 9 daadwerkelijk bereikt konden worden. Dit leverde nog 2 (3\%) reacties op. Om organisatorische redenen was er geen gelegenheid verdere pogingen te ondernemen om alle non-responders telefonisch te bereiken. De totale respons bedroeg derhalve $50 / 76(66 \%)$.

\section{Kenmerken van de respondenten}

De algemene gegevens van de respondenten zijn vermeld in tabel 1. De groep bestond geheel uit vrouwen met een mediane leeftijd van 43 jaar. Ongeveer tweederde van de praktijkondersteuners had een verpleegkundige achtergrond en eenderde was van huis uit doktersassistente. Het merendeel van de respondenten had meer dan 10 jaar werkervaring. De mediane duur van de aanstelling als praktijkondersteuner was 18 maanden en het mediane aantal uur per week dat men als praktijkondersteuner werkte was 18 .

Op de vraag of men in het bezit was van een diploma antwoordden 30 van de respondenten $(60 \%)$ positief. 29 praktijkondersteuners $(58 \%)$ waren al dan niet met een collega-praktijkondersteuner in één huisartspraktijk werkzaam, 21 praktijkondersteuners $(42 \%)$ werkten in meerdere huisartspraktijken.

\section{Aandachtsgebieden}

Het gemiddeld aantal aandachtgebieden per praktijkondersteuner was 4 (range 16). 3 praktijkondersteuners (6\%) hielden zich bezig met één aandachtsgebied, 8 $(16 \%)$ met twee aandachtsgebieden, 10 (20\%) met drie, 20 (40\%) met vier, 5 (10\%) met vijf en 4 praktijkondersteuners ( $8 \%$ ) met zes aandachtsgebieden. Tabel 2 laat zien dat diabetes mellitus, astma/COPD en hart- en vaatziekten de aandoeningen waren waar het grootste aantal praktijkondersteuners zich mee bezighield. Daarnaast werden sociale visites, ouderenzorg en de categorie 'overig' door 30\% of meer van de respondenten genoemd.

\section{Kwaliteit}

Tabel 3 laat zien dat de overgrote meerderheid van de respondenten gebruik maakte van aanvullende protocollen, anders dan die van het Nederlands Huisartsen Genootschap (NHG). Bijstelling van 
Tabel 1 Kenmerken van 50 praktijkondersteuners uit de regio Rijnland en Midden-Holland die deelnamen aan een dwarsdoorsnedeonderzoek naar taken en verantwoordelijkheden in de huisartspraktijk.

\begin{tabular}{|c|c|c|}
\hline & Aantal (\%) & $\begin{array}{r}\text { Mediaan } \\
\text { (range) }\end{array}$ \\
\hline Leeftijd (jaren) & & $43(24-61)$ \\
\hline Geslacht (vrouw) & $50(100 \%)$ & \\
\hline \multicolumn{3}{|l|}{ Beroepsopleiding: } \\
\hline - Verpleegkundige & $33(66 \%)$ & \\
\hline - Doktersassistent & $17(34 \%)$ & \\
\hline \multicolumn{3}{|l|}{ Aantal jaren werkervaring: } \\
\hline - 0-5 jaar & $4(8 \%)$ & \\
\hline - 5-10 jaar & $8(16 \%)$ & \\
\hline - >10 jaar & $38(76 \%)$ & \\
\hline Bezit diploma praktijkondersteuner & $30(60 \%)$ & \\
\hline \multicolumn{3}{|l|}{ Huidige werksituatie: } \\
\hline - 1 praktijkondersteuner, 1 huisartspraktijk & $18(36 \%)$ & \\
\hline - 1 praktijkondersteuner, meer huisartspraktijken & $8(16 \%)$ & \\
\hline - Meer praktijkondersteuners, 1 huisartspraktijk & $11(22 \%)$ & \\
\hline - Meer praktijkondersteuners, meer huisartspraktijken & $13(26 \%)$ & \\
\hline Aantal maanden werkzaam als praktijkondersteuner & & $18(0-72)$ \\
\hline Aantal uren per week werkzaam als praktijkondersteuner & & $18(4-32)$ \\
\hline \multicolumn{3}{|l|}{ Ligging huisartspraktijk(en): } \\
\hline - Stad $>50.000$ inwoners & $17(34 \%)$ & \\
\hline - Stad 10.000-50.000 inwoners & $18(36 \%)$ & \\
\hline - Verstedelijkt dorp 2.000-5.000 inwoners & $8(16 \%)$ & \\
\hline - Groot dorp 1-5.000 inwoners & $5(10 \%)$ & \\
\hline - Klein dorp $<1000$ inwoners & 0 & \\
\hline - Onbekend & $2(4 \%)$ & \\
\hline \multicolumn{3}{|l|}{ Omgeving huisartspraktijk(en):* } \\
\hline - Groeigemeente, veel kinderen & $17(34 \%)$ & \\
\hline - Sterk vergrijsd & $16(32 \%)$ & \\
\hline - Achterstandswijk & $6(12 \%)$ & \\
\hline - Veel allochtonen & $12(24 \%)$ & \\
\hline - Geen bijzondere kenmerken & $21(42 \%)$ & \\
\hline - Onbekend & $1(2 \%)$ & \\
\hline
\end{tabular}

* Meerdere antwoorden zijn mogelijk, waardoor het totaal meer dan $100 \%$ bedraagt.

deze protocollen gebeurde vrijwel altijd in overleg met de huisarts(en). Verder bleken de meeste praktijkondersteuners regelmatig overleg te hebben met collegapraktijkondersteuners, zowel binnen als buiten de eigen huisartspraktijk, over de bijstelling van de richtlijnen zoals neergelegd in de NHG-standaarden.

In het convenant Huisartsenzorg $2-3$ is vastgelegd dat de instelling van de functie van praktijkondersteuner vergezeld dient te gaan van een zogeheten 'plan van aanpak'. Het opstellen van een plan van aanpak was door de zorgverzekeraars als voorwaarde gesteld aan de huisartsen om voor financiële vergoeding in aanmerking te komen. Het plan van aanpak bleek in bijna de helft van de praktijken systematisch te zijn geevalueerd, na een mediane periode van 12 maanden. Deze evaluatie had in ruim de 
Tabel 2 Aandachtsgebieden van 50 praktijkondersteuners uit de regio Rijnland en Midden-Holland

\begin{tabular}{lr}
\hline & Aantal (\%) \\
\hline Diabetes & $43(86 \%)$ \\
Astma/COPD & $38(76 \%)$ \\
Hart- en vaatziekten* & $25(50 \%)$ \\
Diabetes, astma/COPD\# en hart- en vaatzieken & $14(28 \%)$ \\
Sociale visites & $18(36 \%)$ \\
Ouderenzorg & $16(32 \%)$ \\
Wondverzorging & $11(22 \%)$ \\
Gezondheidsvoorlichting en -opvoeding & $7(14 \%)$ \\
Organisatie huisartspraktijk & $10(20 \%)$ \\
Overig & $15(30 \%)$ \\
\hline
\end{tabular}

* Hart- en vaatziekten= hypertensie, hartfalen en cerebrovasculair accident (CVA).

\# COPD = chronic obstructive pulmonary disease.

Tabel 3 Activiteiten in het kader van het kwaliteitsbeleid van 50 praktijkondersteuners uit de regio Rijnland en Midden-Holland.

\begin{tabular}{lrr}
\hline & Aantal (\%) & $\begin{array}{r}\text { Mediaan } \\
\text { (range) }\end{array}$ \\
\hline Gebruik van protocollen anders dan die van het NHG & $39(78 \%)$ & $12(1-14)$ \\
Evaluatie plan van aanpak & $24(48 \%)$ & \\
Duur (maanden) tot evaluatie plan van aanpak & & \\
Wijze van evaluatie plan van aanpak: & $5 / 24(21 \%)$ \\
- Eigen jaarverslag & $10 / 24(42 \%)$ \\
- Overleg met huisarts & $3 / 24(13 \%)$ \\
- Overleg met stuurgroep & $6 / 24(25 \%)$ \\
- Onbekend & $13 / 24(54 \%)$ \\
Bijstelling plan van aanpak op grond van evaluatie & \\
Overleg over kwaliteit:* & $49(98 \%)$ \\
- Met collega-praktijkondersteuners & $34(68 \%)$ \\
- Met huisarts(en) & $20(40 \%)$ \\
Systematische evaluatie kwaliteit functie praktijkondersteuner & $13 / 20(65 \%)$ \\
Verbeteringen naar aanleiding van systematische evaluatie & $31(62 \%)$ \\
Functie praktijkondersteuner als onderdeel van het kwaliteitsjaarverslag & $22(44 \%)$ \\
Eigen jaarverslag werkzaamheden praktijkondersteuner & \\
Uitvoering tevredenheidsmetingen bij patiënten: & $2(4 \%)$ \\
- Regelmatig & $8(16 \%)$ \\
- Incidenteel & $40(80 \%)$ \\
- Nooit & \\
Uitvoering effectiviteitsmetingen bij patiënten: & $6(12 \%)$ \\
- Regelmatig & $11(22 \%)$ \\
- Incidenteel & $33(66 \%)$ \\
- Nooit &
\end{tabular}

* Meerdere antwoorden zijn mogelijk, waardoor het totaal meer dan $100 \%$ bedraagt. 
helft van de gevallen geleid tot een bijstelling van het plan van aanpak.

Vrijwel alle praktijkondersteuners overlegden over de kwaliteit van zorg met 'collega-praktijkondersteuners van binnen en buiten de praktijk: een meerderheid overlegde hierover met de huisarts. De functie van praktijkondersteuner is bij 20 respondenten $(40 \%)$ systematisch geëvalueerd ten aanzien van kwaliteitsaspecten. Dit heeft in 13 van de 20 gevallen (65\%) geleid tot bijstellingen, zoals het bijstellen van protocollen, het aanpassen van taken en het uitbreiden van overlegsituaties. Gemiddeld besteedde de praktijkondersteuner twee uur per week aan kwaliteitsactiviteiten ( $\mathrm{n}=33$; mediaan 2; range $0-10$ ). In ongeveer tweederde van de kwaliteitsjaarverslagen van de huisartspraktijken werd de functie van praktijkondersteuner beschreven. Het kwam tevens voor dat de praktijkondersteuner een eigen jaarverslag maakte. Een minderheid van de praktijkondersteuners voerde effectiviteits- en tevredenheidsmetingen uit bij patiënten.

\section{Aansluiting opleiding en dagelijkse werk- zaamheden van de praktijkondersteuner}

Uit het laatste onderdeel van de vragenlijst kwam naar voren dat ongeveer eenderde van de respondenten de aansluiting van de opleiding met de huidige werkzaamheden als matig tot onvoldoende beoordeelde, zowel ten aanzien van de aandachtsgebieden waarvoor men was opgeleid als qua toerusting voor andere aandachtsgebieden (tabel 4). De behoefte aan aanvullende scholing bleek aanzienlijk, waarbij vooral kennisvermeerdering op het gebied van specifieke ziektebeelden, waaronder diabetes mellitus, astma/COPD en harten vaatziekten, medicatie en computervaardigheden gewenst bleek.

\section{Arbeidssatisfactie}

De arbeidssatisfactie van de praktijkondersteuners was hoog: 33 (66\%) praktijkondersteuners gaven aan dat de nieuwe functie zeer veel tot véél voldoening gaf, 11 respondenten (22\%) ontleenden redelijk veel voldoening aan de functie en 4 respondenten $(8 \%)$ enigszins tot niet. Op de vraag of het functioneren als praktijkondersteuner geleid had tot een salarisverhoging, antwoordden 14 respondenten ja (28\%) en 26 nee (42\%) (een vijftal respondenten gaf aan dat het verdwijnen van de onregelmatigheidstoeslag van invloed was), bij 10 respondenten bleef het antwoord op deze vraag open.

Tenslotte gaven 38 respondenten (76\%) aan behoefte te hebben aan een aparte beroepsvereniging voor praktijkondersteuners. De voornaamste motivatie voor een aparte beroepsvereniging luidde: het is een nieuw beroep waarop de huidige cao-gezondheidszorg niet goed toepasbaar is $(n=10) .5$ respondenten gaven aan de bestaande beroepsverenigingen voor verpleegkundigen voldoende te vinden om voor hun belangen op te komen.

\section{Beschouwing}

Samengevat laat een inventariserend onderzoek onder 50 praktijkondersteuners zien dat de praktijkondersteuner naast de taken behorend bij de aandachtsgebieden waarvoor zij is opgeleid, aanvullende taken heeft op verschillende gebieden. Bijna de helft van de praktijkondersteuners evalueerde op systematische wijze het kwaliteitsbeleid en de kwaliteit van zorg, maar effect- en tevredenheidsmetingen kwamen nog niet vaak voor. De aansluiting van de opleiding tot praktijkondersteuner op de dagelijkse praktijk bleek op verschillende aspecten voor verbetering vatbaar te zijn.

Uit dit onderzoek komt duidelijk naar 
Tabel 4 Tevredenheid van 50 praktijkondersteuners over de afstemming tussen de dagelijkse werkzaamheden en de opleiding tot praktijkondersteuner en de behoefte aan bij-en nascholing.

Aantal (\%)

Aansluiting opleiding en werkzaamheden algemeen:

- Goed

- Ruim voldoende

$11(22 \%)$

- Voldoende

$19(38 \%)$

- Matig

$11(22 \%)$

- Onvoldoende

Aansluiting opleiding met werkzaamheden op het gebied van diabetes mellitus, astma/COPD, hart- en vaatziekten:

- Goed

- Ruim voldoende

$13(26 \%)$

- Voldoende

$13(26 \%)$

$6(12 \%)$

- Matig

- Onvoldoende

$11(22 \%)$

Aansluiting opleiding met andere aandachtsgebieden:

- Goed

- Ruim voldoende

- Voldoende

$14(28 \%)$

- Matig

$11(22 \%)$

- Onvoldoende

- Onbekend

Behoefte aan bij- en nascholing:

- Ja

- Nee

- Onbekend

Onderwerpen voor aanvullende bij- en nascholing:"

- Ziektebeelden algemeen

- Diabetes mellitus

- Astma/COPD

- Hart- en vaatziekten

$13(26 \%)$

- Medicatie

$12(24 \%)$

- Computervaardigheden

$30(60 \%)$

- Organisatie van de huisartspraktijk

$20(40 \%)$

- Diagnostiek en methodisch handelen

$16(32 \%)$

- Kwaliteitsbeleid

$13(26 \%)$

- Medisch-technische vaardigheden

- Sociale vaardigheden

- Gezondheidsvoorlichting en -opvoeding

\# Meerdere antwoorden zijn mogelijk, waardoor het totaal meer dan $100 \%$ bedraagt. 
voren dat de meeste praktijkondersteuners zich bezighouden met de drie aandachtsgebieden waaraan in de opleiding de meeste aandacht is besteed, maar dat zij zich daarnaast met diverse andere zorgcategorieën bezighouden. Een kwart van de praktijkondersteuners gaf echter aan zich onvoldoende toegerust te voelen om in andere aandachtsgebieden werkzaam te zijn. Uit eerder onderzoek ${ }^{2}$ is gebleken dat vooral de ervaring en achtergrond van de praktijkondersteuner bepalend zijn voor de aard van de zorgcategorieën waarop deze zich richt. Kennis en vaardigheden op het gebied van andere zorgcategorieën dan de drie aandachtsgebieden waarop de opleiding zich tot nu toe heeft gericht, lijkt gezien deze resultaten belangrijk voor toekomstig initieel of vervolgonderwijs voor praktijkondersteuners.

Wat het kwaliteitsbeleid betreft blijkt veel gebruik gemaakt te worden van protocollen, veelal ook protocollen die niet door het NHG zijn ontwikkeld. In de helft van de gevallen was sprake van een formele evaluatie van het plan van aanpak. Ook de functie van praktijkondersteuner werd binnen de praktijk in een minderheid van de gevallen formeel geëvalueerd. Mogelijk heeft de relatief korte gemiddelde duur waarbinnen de praktijkondersteuners werkzaam waren hierin een rol gespeeld.

Opvallend is het geringe aantal praktijkondersteuners dat daadwerkelijk directe metingen van kwaliteit van patiëntenzorg, zoals effectiviteits- en tevredenheidsmetingen, uitvoert. Nader onderzoek is nodig om te inventariseren wat hiervan de reden kan zijn, zoals een gebrek aan tijd of onvoldoende kennis over of ervaring met het systematisch uitvoeren van metingen. Dit laatste is minder waarschijnlijk, omdat weliswaar een deel van de respondenten aangaf meer scholing te wensen op het gebied van kwaliteitsbeleid, maar het uitvoeren van effectiveits- en tevredenheidsmetingen in de toelichting door geen van de respondenten werd genoemd. Omdat kwaliteitsbeleid de komende jaren een steeds belangrijkere rol zal gaan spelen in de huisartsenzorg, zal de rol van de praktijkondersteuner meer aandacht behoeven, hetgeen zowel in de basisopleiding als in nascholingsactiviteiten geëffectueerd kan worden.

Naast de hierboven genoemde onderwerpen kwam uit het onderzoek naar voren dat de opleiding tot praktijkondersteuner op een aantal andere punten te weinig aansloot bij de praktijksituatie. Met name kennis op het gebied van de organisatie van de huisartspraktijk en technische en computervaardigheden blijken binnen de opleiding te weinig aan bod te zijn gekomen. Het bovenstaande roept dan ook de vraag op of het curriculum van de opleiding tot praktijkondersteuner herzien moet worden of dat bij- en nascholing noodzakelijk zijn.

De bevindingen van dit onderzoek dienen met enige voorzichtigheid te worden geïnterpreteerd. Het onderzoek is uitgevoerd in slechts één regio, waardoor het aantal praktijkondersteuners dat benaderd werd beperkt was. Hoewel een respons van $66 \%$ redelijk is, zou het kunnen zijn dat er een verschil bestaat tussen de kenmerken en opvattingen van praktijkondersteuners die wel en niet aan het onderzoek hebben deelgenomen. Met een groter, landelijk opgezet onderzoek, met gebruikmaking van aanvullende methoden om de respons te verhogen, zou aan de beperkingen van het huidige onderzoek tegemoet gekomen kunnen worden.

In 2000 werd in Nederland gestart met de opleiding Master Advanced Nursing Practice, ofwel de nurse practitioner (NP). Enige tijd later kwam daar de opleiding tot physician assistant (PA) bij. De ontwikkeling van de functies van nurse practitioner en physician assistant in Nederland zijn 
voornamelijk gelegen in de capaciteitsproblematiek (een tekort aan artsen). ${ }^{7}$ De overheid, gezondheidszorginstellingen, beroepsbeoefenaren en zorgverzekeraars proberen gezamenlijk deze problemen op te lossen door een verschuiving van taken in gezondheidszorg. De praktijkondersteuner in de huisartspraktijk heeft in dit proces een voortrekkersfunctie gehad.

Op dit moment staan de opleidingen van nurse practitioner en physician assistant volop in de belangstelling. Beide opleidingen doen, zij het in bescheiden mate, ook hun intrede in de huisartspraktijk. De vraag rijst welke gevolgen dit heeft voor de positie van de praktijkondersteuner. De LHV heeft inmiddels laten weten erg tevreden te zijn over het functioneren van de praktijkondersteuner. De vereniging pleit dan ook voor het vrijmaken van budget voor het continueren van de opleiding tot praktijkondersteuner. In verband hiermee kan het van belang zijn dat praktijkondersteuners zich organiseren, bijvoorbeeld in de vorm van een beroepsvereniging. Uit het huidige onderzoek kwam naar voren dat de meerderheid van de praktijkondersteuners hieraan ook behoefte heeft.

\section{Dankwoord}

Dit onderzoek werd mede mogelijk gemaakt met de hulp van vier praktijkondersteuners: Marja van Rossum en Jeanette van Haaster, verbonden aan het Gezondheidscentrum Wantveld te Noordwijk, en Petra Smids-de Jong de Leeuw en Lies van Driel-Stouten, verbonden aan de Huisartspraktijk Maasdam te Maasdam.

Ook danken wij drs. Jan Schoones, als bibliothecaris verbonden aan het Leids Universitair Medisch Centrum te Leiden. Zijn kennis en vaardigheden op het gebied van literatuuronderzoek waren van grote waarde voor het onderzoek.

\section{Literatuur}

1. Taakherschikking in de gezondheidszorg. Advies uitgebracht door de Raad voor de Volksgezondheid en Zorg aan de minister van Volksgezondheid, Welzijn en Sport. Zoetermeer: RVZ; 2002 [geciteerd 10 januari 2006]. Beschikbaar op: http://www.rvz.net/ data/download/advies_taakherschikking.pdf.

2. Berg $\mathbf{M}$ van den, Bakker $\mathbf{D}$ de. Meta-analyse. Introductie praktijkondersteuning op HBO-niveau in de huisartsenpraktijk in Nederland [rapport]. Utrecht: NIVEL; 2003 [geciteerd 10 januari 2006]. Beschikbaar op: http://www.nivel.nl/pdf/praktijkondersteuning-hbo-huisartsenpraktijk.pdf.

3. Praktijkondersteuning huisartsen. Werkdocument functieomschrijving en competenties \& praktijkondersteuner (HBO). Utrecht: Landelijke Huisartsen Vereniging; mei 2001.

4. Praktijkondersteuning huisartsen. Werkdocument competenties en eindtermen, versie 2004. Utrecht: Landelijke Huisartsen Vereniging; april 2004.

5. Bouwstenen Zorg in de Buurt. Verkennende ambtelijke notitie versterking huisartsenzorg/eerstelijnsgezondheidszorg. Ministerie van Volksgezondheid, Welzijn \& Sport (VWS) en Ministerie van Financiën; maart 2003.

6. Lamkaddem MI, Bakker D de, Nijland A, Haan J de. De invloed van praktijkondersteuning op de werklast van huisartsen. Een analyse van gegevens uit het Landelijk Informatie Netwerk Huisartsenzorg [rapport]. Utrecht: NIVEL; 2004 [geciteerd 10 januari 2006]. Beschikbaar op: http:// www.nivel.nl/pdf/invloed-praktijkondersteuningop-werklast-huisartsen.pdf.

7. Offenbeek MAL van. Een waaier van nieuwe functies. Med Contact 2002;57(21):817-21.

\section{De auteurs:}

Drs. I.B.O.M. Lohman, Hogeschool Leiden, lectoraat en kenniskring Mensen met een Chronische Ziekte.

Drs. A.R.S. Wijsbeek, Hogeschool Leiden, lectoraat en kenniskring Mensen met een Chronische Ziekte.

Dr. F.W. Dijkers, afdeling Huisartsgeneeskunde en Verpleeghuisgeneeskunde, Leids Universitair Medisch Centrum.

Drs. A.P. Timmers, Gezondheidscentrum Wantveld, Noordwijk.

E. Zonnevylle, Districts Huisartsenvereniging Rijnland en Midden-Holland, thans REOS-Zorg Leiden.

P.B.M. van der Linden, Hogeschool Leiden, afdeling Verpleegkunde.

Dr. T.P.M. Vliet Vieland, Hogeschool Leiden, lectoraat en kenniskring Mensen met een Chronische Ziekte.

\section{Correspondentieadres:}

Drs. I.B.O.M. Lohman en drs. A.R.S. Wijsbeek, Hogeschool Leiden, afdeling Verpleegkunde, Zernikedreef 11, 2333 CK Leiden, tel.: 06-48133621, lohman.i@hsleiden.nl of wijsbeek.a@hsleiden.nl. 


\section{Summary}

Introduction: In 2001, courses were introduced to train physician assistants. The main function of the physician assistant is to alleviate general practitioners' workload. We examined actual performance of the tasks and competencies taught in the course by physician assistants in day to day practice and whether they performed different tasks or tasks in addition to those taught in the course. We also examined the practical relevance of the course.

Method: A questionnaire was sent to 76 physician assistants employed in the region of one District General Practitioners Association. The questionnaire consisted of a total of 54 multiple choice questions and open questions about training and experience, present employment and job content, implementation of quality assurance and the relevance of the course for day to day practice.

Results: Fifty out of 76 physician assistants responded (66\%). The respondents were all female, median age was 43 years (range 24-61) and median length of employment as a physician assistant was 18 months (range 0-72). The median number of areas of interest was 4 (range 1-6), the most frequently mentioned ones being diabetes mellitus $(n=43 ; 86 \%)$, asthma and chronic obstructive pulmonary disease (COPD) $(n=38 ; 76 \%)$ and cardiac and arterial disease $(n=25 ; 50 \%)$. The number (percentage) of respondents seeing social calls as her area of interest was $18(36 \%)$ and for care for the elderly, wound dressing, practice organisation, health education and other subjects these numbers were 16 (32\%), 11 (22\%), 10 (20\%), 7 (14\%) and 15 (30\%), respectively. The initial job descriptions of 24 (48\%) of the physician assistants had been evaluated and had resulted in modifications of half of these. Quality of care was systematically evaluated by $30 \%$ of the respondents, with measurement of quality of care being relatively rare (regular measurement of effectiveness was reported by $12 \%$ and measurement of satisfaction by $4 \%$ ). The most frequently suggested topics for future continuing professional development activities were: signs and symptoms of disease, medication, diagnosis and systematic working practices, computer skills and quality management. Overall personal job satisfaction was high.

Conclusions: Physician assistants perform a number of different tasks in addition to those related to the areas of interest covered by their training. Almost half of the respondents evaluate quality management and quality of care systematically, although measurements of effectiveness and satisfaction are rare. There are several areas where the relevance to day-to-day practice of physician assistant training courses can be improved. (Lohman IBOM, Wijsbeek ARS, Dijkers FW, Timmers AP, Zonnevylle E, Linden PBM van der, Vliet Vlieland TPM. The physician assistant in general practice: competency profile and day to day practice. Dutch Journal of Medical Education 2006;25(1):29-38.) 